\title{
O ESPAÇO E AS LEIS: ESTRATÉGIAS PARA O PLANEJAMENTO DA CÂMARA DOS DEPUTADOS ${ }^{1}$
}

\author{
Valério Augusto Soares de Medeiros ${ }^{2}$
}

Resumo: O artigo apresenta discussões e resultados a respeito das relações entre o espaço físico da Câmara dos Deputados brasileira e a realização das atividades referentes ao processo legislativo. Procura-se interpretar de que maneira o ambiente construído e a arquitetura da Casa Legislativa promovem ou atravancam a organização e o funcionamento do parlamento. $\mathrm{O}$ método adotado foi o estudo comparado e descritivo e os principais resultados apontam a necessidade de se construir um sistema de informações para gerenciamento e planejamento dos espaços físicos na Câmara dos Deputados.

Palavras-chave: Câmara dos Deputados; Processo Legislativo; Espaço Físico; Sintaxe Espacial.

Abstract: This paper presents discussions and findings about the relationships between the Brazilian Chamber of Deputies built space and the development of activities associated with the legislative process. It aims to explore to what extent the built environment and the configuration of the Legislative House foster or restrain the organization and performance of the Parliament. The method used was descriptive and comparative study and the main results suggest the need to build an information system for management and planning of physical spaces in the Chamber of Deputies.

Key words: Chamber of Deputies; Legislative Process; Built Space; Space Syntax.

\section{Introdução: Contextualizando o Cenário}

O Poder Legislativo brasileiro "cumpre papel imprescindível perante a sociedade do País, visto que desempenha três funções primordiais para a consolidação da democracia: representar o povo brasileiro, legislar sobre os assuntos de interesse nacional e fiscalizar a

\footnotetext{
${ }^{1} \mathrm{O}$ texto deriva de uma versão preliminar apresentada durante o IV Encontro PROJETAR, realizado em outubro de 2009 na Faculdade de Arquitetura e Urbanismo da Universidade Presbiteriana Mackenzie, em São Paulo - SP. O artigo, intitulado "Analisar, avaliar e programar: insumos para projetos na Câmara dos Deputados", foi elaborado em coautoria com os arquitetos Frederico de Holanda, Edja Trigueiro, Valéria Carvalho e Élcio Gomes, aos quais agradeço a colaboração.

${ }^{2}$ Analista Legislativo da Câmara dos Deputados, lotado na Coordenação de Projetos do Departamento Técnico da Casa. É professor do Curso de Especialização em Gestão Pública Legislativa do Cefor/Câmara dos Deputados, Pesquisador colaborador do Programa de Pesquisa e Pós-Graduação da Faculdade de Arquitetura e Urbanismo de Brasília (FAU/UnB) e professor do Centro Universitário Unieuro. (medeiros.valerio@uol.com.br)
} 
aplicação dos recursos públicos"3. Para que o Legislativo exerça adequadamente suas funções ${ }^{4}$, é imprescindível a existência de uma série de suportes, a incluir aqueles de natureza humana (servidores), financeira (dotação orçamentária) ou espacial (espaços físicos), entre outros, que possibilitem o desempenho das atividades parlamentares a resultarem em última instância na execução das leis.

No âmbito espacial, o suporte significa a disponibilização de toda uma estrutura arquitetônica (os edifícios de função legislativa e seus ambientes), urbana (tais edifícios e a cidade) e material (a distribuição de mobiliário nos ambientes), que forneça os invólucros. A unidade básica são as áreas de trabalho para que as atividades de organização e funcionamento do parlamento ali aconteçam (pronunciamentos, cerimônias, debates, execução de instâncias processuais, etc.).

Esses espaços, em tese, precisariam adequadamente atender às expectativas de variados grupos de usuários vinculados aos procedimentos de elaboração das leis (parlamentares, servidores, credenciados, visitantes, etc.), a observar os aspectos: (a) funcionais (o lugar satisfaz as exigências práticas em termos de tipo e quantidade de espaços para as atividades, e seu interrelacionamento?); (b) econômicos (os custos de implementação, manutenção e uso dos espaços são compatíveis com a instituição?); (c) bioclimáticas (há condições de conforto físico para os usuários?); (d) topoceptivas (o lugar é legível visualmente, isto é, tem uma identidade? O lugar oferece boas condições para a orientabilidade?); (e) afetivos (o lugar tem uma personalidade afetiva? Como ele afeta o estado emocional das pessoas?); (f) simbólicos (o lugar é rico em elementos arquitetônicos que remetam a outros elementos, maiores que o lugar, ou a elementos de natureza diversa - valores, idéias, história?); (g) estéticos (o lugar é belo?); e (h) sociológicos/copresenciais (a configuração do lugar implica maneiras desejáveis dos usuários localizarem-se nos lugares e de se moverem por eles, produzindo condições desejadas para encontros e esquivanças interpessoais? $)^{5}$.

A interpretação produz alguns questionamentos sobre o tema - (a) como mensurar, quantificar e acompanhar a maneira pela qual o espaço físico responde às expectativas dos usuários em um determinado complexo arquitetônico?; e (b) no caso particular da Câmara dos Deputados, como a estrutura física resultando de seus bens imóveis colabora, ou não, para a organização e funcionamento do parlamento, com vistas à promoção das atividades políticoparlamentares e do processo legislativo? - de que resultou uma promissora inquietação sobre

\footnotetext{
${ }^{3}$ Cf. $<$ www.camara.gov.br/conheca >.

${ }^{4}$ Legislar e exercer uma série de atos de controle do Executivo, conforme os artigos de 48 a 52 da Constituição Federal

${ }^{5}$ Cf. Holanda (2007), a partir da técnica de análise dimensional para a investigação da arquitetura desenvolvida pelos professores Frederico de Holanda, Maria Elaine Kohlsdorf e Günter Kolsdorf, da Faculdade de Arquitetura e Urbanismo da Universidade de Brasília.
} 
como a estrutura espacial da Câmara dos Deputados $^{6}$ vem interferindo na realização das rotinas diárias e ações cujo foco é a elaboração de leis, conforme atribuição precípua do Congresso Nacional.

Sabendo-se que uma boa sincronia entre a organização espacial e o desempenho das atividades $^{7}$ significa a melhora na realização dos procedimentos de natureza finalística para a $\mathrm{Casa}^{8}$, bem como pressupõe a sincronia com atividades-meio, de suporte, o artigo apresenta discussões e resultados a respeito das relações entre (a) o espaço físico da Câmara dos Deputados e (b) a realização das atividades referentes ao processo legislativo. Procura-se interpretar de que maneira o ambiente construído e a arquitetura da Casa promovem ou atravancam a organização e o funcionamento do parlamento brasileiro. Corresponde a levantar, quantificar e estabelecer como fatores associados à configuração espacial (dimensões, distâncias, proporções, organização espacial, etc.) afetam a realização das atividades do legislativo brasileiro.

É interesse, portanto, obter um diagnóstico espacial e estabelecer as rotinas futuras para tarefas relacionadas e afins, conforme a definição de indicadores para racionalizar a realização das atividades finalísticas da Casa. Parte-se do pressuposto que os primeiros resultados aqui descritos tornarão mais claros e palpáveis os produtos oriundos do planejamento espacial. Ademais, fornecerão subsídios para delimitar: (1) níveis de carências e desígnios para o bom desempenho da Casa, em termos das relações entre estrutura espacial e atividades cotidianas do parlamento; (2) o escopo futuro de iniciavas de planejamento, associando-se ao Planejamento Estratégico global da Câmara dos $\operatorname{Deputados}^{9}$ e; (3) produtos desejados, em níveis diferenciados e considerados os prazos curto, médio e longo.

\section{A Câmara dos Deputados: Pressupostos}

A Câmara dos Deputados tem por suporte físico, para o funcionamento de suas atividades fim e meio, um complexo arquitetônico que totaliza aproximadamente $150.000 \mathrm{~m}^{2} \mathrm{de}$ área construída em edificações situadas no entorno ou ao longo do Eixo Monumental, em Brasília (Figura 01). Além do Edifício Principal e do Anexo I, que juntos compõem o Palácio do Congresso Nacional (Figura 02) ${ }^{10}$, são parte do conjunto os prédios do Anexo II, Anexo III, Anexo IV e Bloco de Lideranças Partidárias, resultando no denominado Complexo Arquitetônico Principal. Complementarmente, próximo à Praça dos Três Poderes, está disposto o Complexo Avançado da Casa, a incluir o edifício sede do Centro de Formação, Treinamento e

\footnotetext{
${ }^{6}$ A incluir avaliações sobre saturação espacial, fragmentação de unidades, distâncias entre ambientes, qualidade do ambiente de trabalho, etc.

${ }^{7}$ Ver recentes discussões em Appel-Meulenbroek, 2009; SAILER e PENN, 2009 e STEEN, 2009.

8 São exemplos: processo legislativo, atividade político parlamentar, técnica legislativa e pronunciamento parlamentar

${ }^{9}$ Conduzido pela Assessoria de Projetos Especiais e Gestão Estratégica/APROGE-DG.
} 
Aperfeiçoamento - Cefor e aquele compartilhado entre a Gráfica e a Coordenação de Transportes.

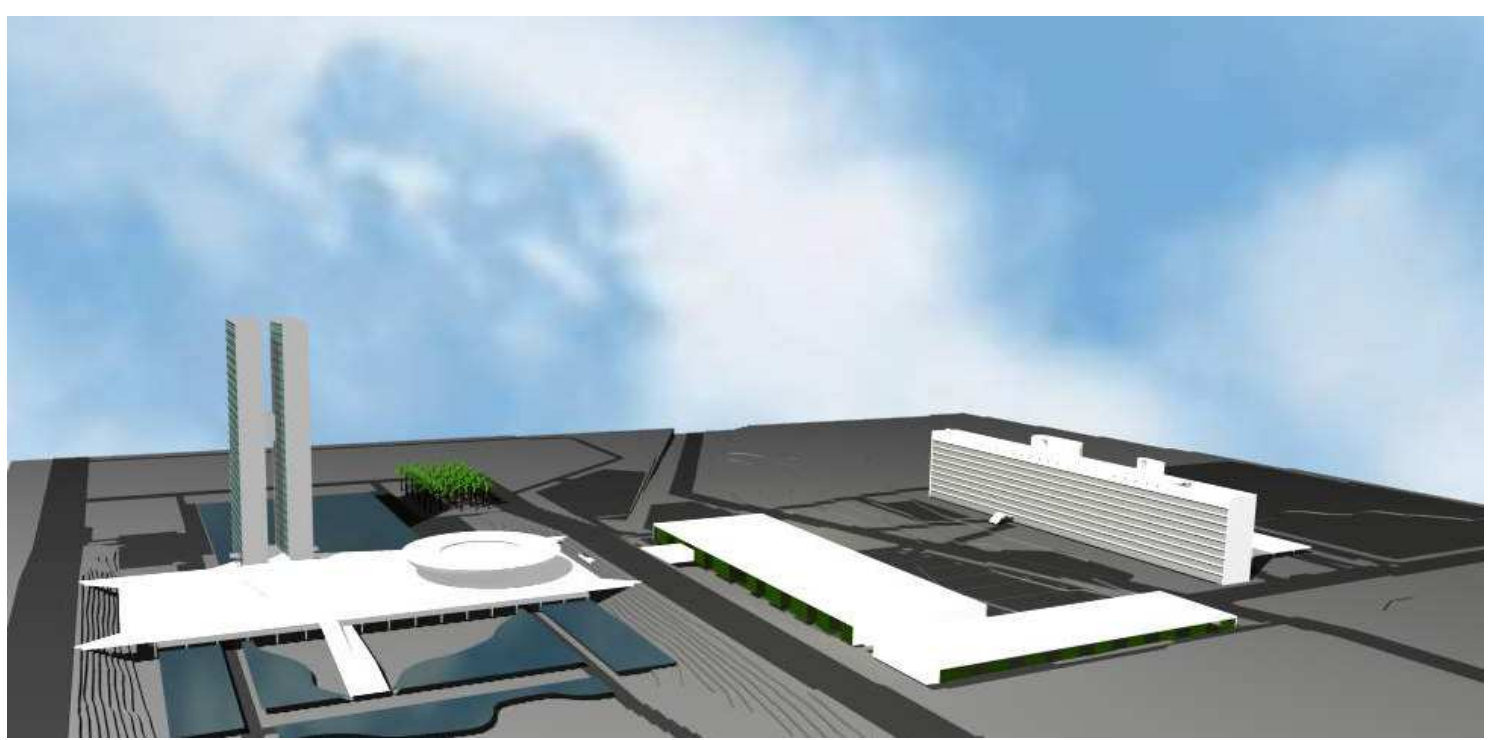

Figura 1 - Complexo Arquitetônico Principal da Câmara dos Deputados. Fonte: CPROJ/DETEC/CD.

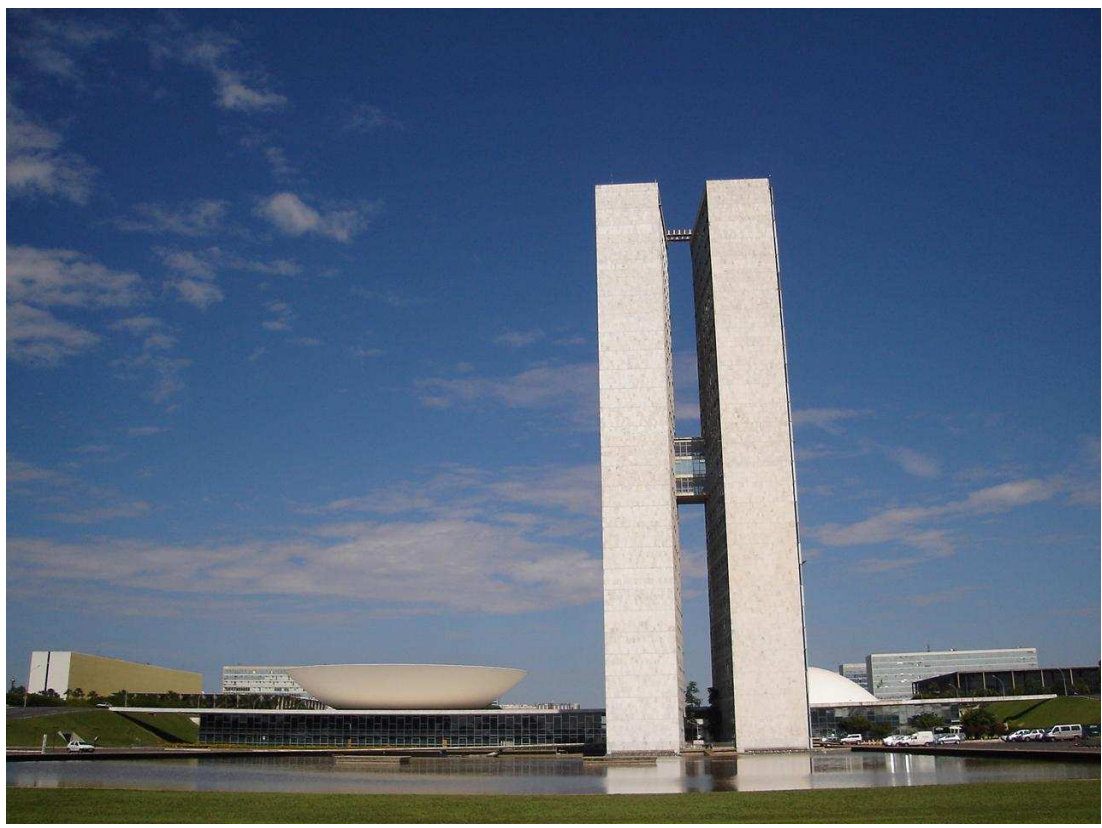

Figura 2 - Palácio do Congresso Nacional, em Brasília. Crédito: Valério Medeiros.

Por estes espaços, conectados segundo uma série de corredores, esteiras, rampas de acesso e sistemas de transporte motorizados, circulam diariamente entre 20.000 e 30.000 pessoas, população superior a mais de $74 \%$ dos municípios brasileiros ${ }^{11}$. Dado que deve ser acrescido do quadro de pessoal da instituição que, ademais os 513 Deputados, é composto por

\footnotetext{
${ }^{10}$ A composição, associada aos prédios equivalentes do Senado Federal, define o ponto de fuga expressivo e simbólico da perspectiva estabelecida por Lucio Costa para a Escala Monumental do Plano Piloto, em Brasília - DF. ${ }^{11} \mathrm{Cf}$. dados populacionais do IBGE.
} 
cerca de 10.000 funcionários em Brasília, entre servidores efetivos, Cargo de Natureza Especial - CNEs, secretários parlamentares e terceirizados (CT01, 2007).

A dimensão, a escala e a população circulante diariamente nas dependências da Câmara dos Deputados permitem a comparação de sua estrutura espacial como uma cidade: ali são encontrados serviços diversos (agências bancárias, companhias aéreas, restaurantes, lanchonetes, bancas de revista, agência dos Correios, barbearia, farmácia, áreas de exposição, etc.), que garantem a vitalidade e o funcionamento da instituição, transformando-a em um dos mais complexos locais da capital brasileira.

A considerar a diversidade de interesses em ação na Câmara dos Deputados, a despeito de uma aparente unidade no conjunto arquitetônico e em seus respectivos ambientes internos, ali existem significativos problemas associados a espaços físicos. É senso comum: (a) o aspecto labiríntico do conjunto arquitetônico, comprometendo a acessibilidade e a circulação internas para funcionários ou visitantes; (b) a fragmentação de atividades e adaptação de usos; bem como (b) são recorrentes as negativas para solicitações de novos espaços encaminhadas ao Departamento Técnico/Detec da instituição, em razão da indisponibilidade de área para atendimento de novas demandas.

É sabido que as condições do espaço interferem na qualidade e resultado do trabalho. Tais condições podem ser mensuradas por meio de variáveis: físico-ambientais (iluminação, ventilação, temperatura); configuracionais (setorização, relações de proximidade entre atividades interligadas, adaptação/alteração de usos) e de ocupação (densidades), seguindo a linha da interpretação dimensional que remete aos aspectos funcionais, bioclimáticos, econômicos, sociológicos, topoceptivos, afetivos, simbólicos e estéticos (cf. nota 4).

\section{Teoria, Metodologia e Técnicas}

A produção do estudo considerou preliminarmente a etapa de levantamento empírico, a compreender dados a serem obtidos conforme uma série de coletas in loco, e informações de natureza ou implicação espacial solicitadas aos órgãos pertencentes à estrutura organizacional da Casa (estatísticas sobre população existente, distribuição de servidores, localização espacial, ocupação atual, legislação afim, rotinas de trabalho, cadastro de atividades, etc. ).

Para a investigação de questões de configuração espacial foram adotados os aparatos da Teoria da Lógica Social do Espaço. Para o registro e controle das informações, o conjunto de dados foi inserido em um Sistema de Informação Geográfica ou SIG (técnica de geoprocessamento, por meio do software ArcGIS 9.3®), para melhor performance no tratamento e elaboração das análises. 


\subsection{A teoria da sintaxe espacial}

Emprega-se a Teoria da Sintaxe Espacial, ou Teoria da Lógica Social do Espaço (Hillier e Hanson, 1984; Hillier, 1996), baseada no pensamento sistêmico (Capra, 2003) e estruturalista. A abordagem contempla técnicas de entendimento e representação do espaço, gera subsídios que permitem ao pesquisador investigá-lo do ponto de vista das articulações, descreve possibilidades de interação a partir de possíveis fluxos diferenciados de pessoas ou veículos. Equivale à exploração dos espaços ou vazios deixados pelos cheios na cidade ou no edifício, o que avaliza a associação ao conceito de forma-espaço (Medeiros, 2006) ${ }^{12}$.

Mediante um método e técnicas, a teoria da sintaxe espacial estabelece relações entre atributos de duas instâncias: (a) o espaço organizado para fins humanos (escalas do edifício e da cidade); e (b) a estrutura social, os modos de interação entre indivíduos e grupos, clivagens sociais e estruturas de poder.

Segundo Hillier (2001), se nós colocarmos um objeto aqui ou ali, dentro de um sistema espacial, certas conseqüências previsíveis afetarão a configuração espacial do ambiente. Esses efeitos são bastante independentes dos desejos ou da intenção humana, mas podem ser utilizados pelos seres humanos para alcançarem efeitos espaciais e mesmo sociais. O espaço não é um elemento passivo. É também uma variável independente.

A sintaxe espacial, portanto, estabelece uma relação fundamental entre a configuração do espaço e o modo como este espaço funciona, o que permite determinar alguns aspectos do seu funcionamento que outras abordagens não são capazes de explorar. Das maneiras de representação que são recomendados pela abordagem (espaços convexos, campos visuais e linhas), a linear é útil para a investigação do movimento e dos vários aspectos relacionados a ele. É a que melhor se aplica a grandes sistemas e estruturas, como a cidade ou edifícios complexos, como ocorre no caso da Câmara dos Deputados ${ }^{13}$.

A representação linear é obtida traçando-se sobre o sistema de circulação (malha viária em uma cidade ou corredores de circulação, para edificações), a partir da base cartográfica/planta disponível, o menor número possível de retas que representam acessos diretos através da trama. Após o processamento destas retas, pode-se gerar uma matriz de interseções, a partir da qual são calculados, por aplicativos especialmente programados para este $\mathrm{fim}^{14}$, valores representativos de suas inter-relações axiais, denominados "de integração”. Esses

\footnotetext{
${ }^{12} \mathrm{O}$ termo forma-espaço é emprestado de Holanda (2007) e se refere ao estudo dos vazios, cheios e suas relações; o autor ampara-se no conceito de Evaldo Coutinho (1998), ao interpretar a arquitetura em seus componentes-meio (cheios, sólidos, maciços, invólucros: a forma) e componentes-fim (vão, vazios, ocos: o espaço).

${ }^{13}$ A escolha da representação linear se ampara na questão cognitiva das estratégias que os seres humanos utilizam ao percorrer os trajetos. Segundo Hillier (2001), se nossas representações cognitivas do espaço complexo são de fato geometricamente descontínuas, percebemos o espaço como montagens de elementos geométricos interrelacionados e não como padrões complexos de distâncias métricas. Portanto, a forte candidata como elemento na geometria descontínua seria a linha. "As linhas apresentam as duas propriedades-chave de serem tanto muito simples quanto globais. Tudo o que precisamos saber é quanto conseguimos ver a partir de um ponto".

${ }_{14}$ Axman $^{\circledR}$, Orange Box ${ }^{\circledR}$ e Ovation ${ }^{\circledR}$ para computadores Macintosh; e Spatialist ${ }^{\circledR}$, Axwoman ${ }^{\circledR}$, Depthmap ${ }^{\circledR}$ e Mindwalk $^{\circledR}$, para PCs.
} 
valores podem ser representados numericamente ou numa escala cromática com gradação indo do vermelho, passando pelo laranja e verde até chegar ao azul - onde os eixos com maior valor de integração tendem a vermelho, e os de menor, a azul ${ }^{15}$. O resultado é o denominado mapa axial (Figura 3).

Isso permite consequentemente a visualização de uma malha de movimento em gradações de potenciais de fluxos e movimentos, isto é, de integração. Torna-se perceptível a definição de áreas com predominância de eixos de grande potencial de movimento em oposição àquelas áreas periféricas de menor fluxo.

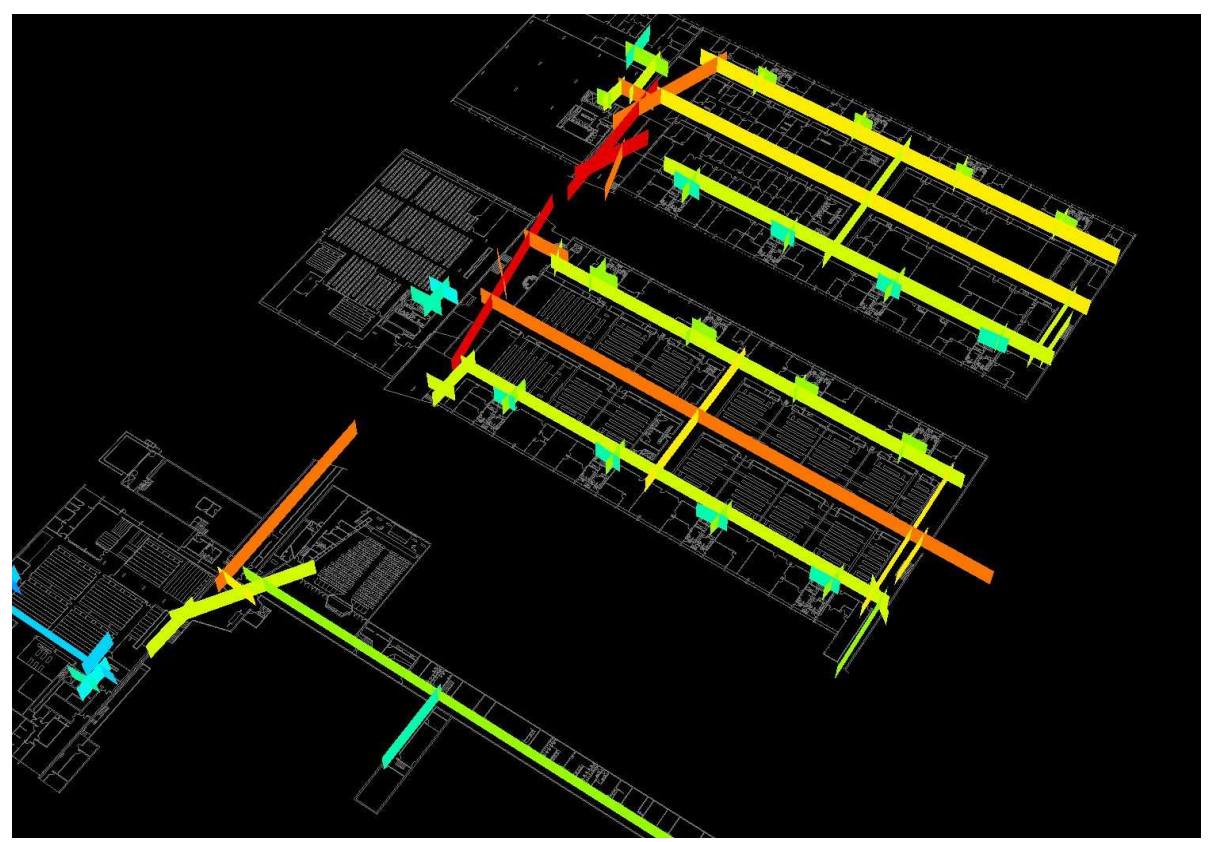

Figura 3 - Detalhe do mapa axial do Edifício Anexo II da Câmara dos Deputados.

Têm-se, dessa maneira, uma ferramenta valiosa para estudos espaciais e de design ao possibilitar que fatores relacionados à disposição dos espaços (configuração) sejam matematicamente mensurados e claramente visualizados e, portanto, possam ser correlacionados com a infinidade de informações que envolvem estudos urbanos ou de edifícios complexos. Tais correlações podem ser produzidas a partir dos diversos requisitos espaciais demandados pelos usuários, conforme as incidências sobre as atividades legislativas, como no caso da Câmara. Além disso, permitem a simulação de cenários futuros a partir da avaliação das alterações físicas porventura previstas.

\footnotetext{
${ }^{15}$ Eixos mais integrados são aqueles mais permeáveis e acessíveis no espaço, de onde mais facilmente se alcançam os demais. Implicam, em média, os caminhos topologicamente mais curtos para serem atingidos a partir de qualquer eixo do sistema. Eixos mais integrados tendem a assumir uma posição de controle, uma vez que podem se conectar a um maior número de eixos e hierarquicamente apresentam um potencial de integração superior. Ao conjunto de eixos mais integrados se dá o nome de núcleo de integração.
} 


\subsection{Geoprocessamento/SIG}

A base de dados oriunda da pesquisa - incluindo as bases cartográficas e XREFs, as representações lineares e os mapas axiais analisados - está inserida no aplicativo Arcview/ArcGIS $9.3{ }^{\circledR}$, um software de geoprocessamento que congrega em um mesmo banco informações vetoriais (mapas) e dados diversos, otimizando o tratamento de dados.

A opção por um banco de dados georreferenciado e pela utilização de um SIG deve-se às possibilidades de manipulação que um sistema como este pode oferecer. Segundo Foresti e Hamburger (1995), o conhecimento da distribuição espacial das diversas formas de ocupação do espaço necessita de um sistema de informações detalhadas que possam ser consultadas com grande frequiência devido ao caráter extremamente dinâmico do ambiente.

\section{Resultados}

O conjunto de informações levantadas foi disposto na base georeferenciada de dados, o que tem servido de subsídio para a elaboração de análises, pareceres e instruções processuais. Além disso, o sistema contempla as primeiras experiências em direção à composição de um plano diretor de ocupação dos espaços físicos para a Câmara dos Deputados. A seguir, são detalhadas informações sobre alguns dos produtos resultantes das análises, a incluir experiências e achados.

\subsection{A elaboração dos cadernos técnicos}

Desde dezembro de 2006, no âmbito da Coordenação de Projetos do Departamento Técnico da Casa, vem sendo produzidos cadernos técnicos, discutindo aspectos relacionados aos espaços físicos associados à instituição. Dois dos exemplos são apresentados nos itens 4.1.1 e

\subsection{2.}

\subsubsection{CT01 - Planejamento dos Espaços Físicos (março de 2007)}

O caderno compreendeu uma pesquisa de avaliação inicial dos procedimentos aplicáveis ao planejamento dos espaços físicos na Câmara dos Deputados, baseando-se em (1) dados coletados por meio de variadas fontes (departamentos e coordenações) e (2) observações empíricas (coletadas in loco e em fontes primárias). Quanto aos temas, foram ponderando aspectos de: (1) população e densidades (saturação e demandas por espaços); (2) fluxos 
(circulação ao longo dos edifícios); (3) ocupação (uso efetivo atual); (4) potenciais construtivos (possibilidades de incremento de área a partir de novos terrenos e lotes já doados ou em processo de doação à Câmara). A execução da rotina de trabalho vinculada ao caderno foi conduzida segundo o interesse em obter um diagnóstico, além de estabelecer as rotinas futuras para tarefas relacionadas.

O material alinhou-se aos objetivos do documento "Elaboração da Proposta do DETEC para o Plano Plurianual - PPA 2008/2011", divulgado em 11 de dezembro de 2006 pela Assessoria do Detec/Câmara dos Deputados, na categoria "Estudos Técnicos Elaborados pelas Coordenações". Os resultados obtidos até então tinham se mostrado úteis para discussões associadas ao PPA e serviram de subsídio para a definição das ações correlatas desta Coordenação de Projetos do Detec.

De março de 2007 até o presente, o caderno (CT01, 2007) tem sido utilizado como subsídio técnico para os pareceres processuais despachados pela Seção de Gerenciamento e Planejamento do Espaço Físico do Núcleo de Arquitetura (CPROJ/Detec). As conclusões sobre indisponibilidade de espaço tem sido úteis para demonstrar a necessidade de reordenamento e remanejamento entre órgãos internos da Câmara, de modo a amenizar os conflitos por distribuição de área.

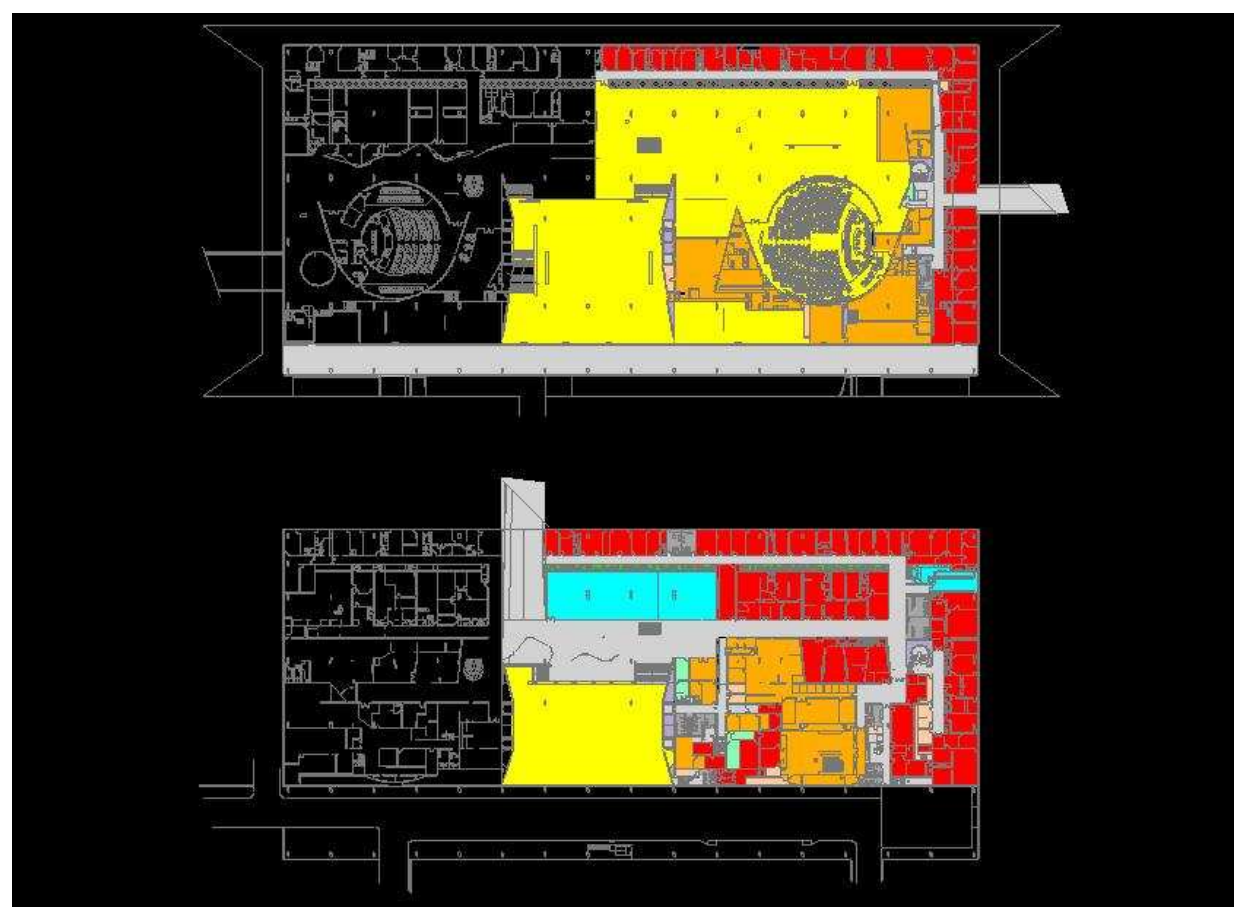

Figura 4 - Ilustração de parte do mapa de uso e ocupação dos espaços na Câmara: Edifício Principal. 


\subsubsection{CT04 - Acessibilidade Viária \& Estacionamento (maio 2007)}

Este Caderno Técnico (CT04, 2007) compreendeu um estudo exploratório e preliminar a respeito da problemática da acessibilidade viária e do quantitativo de vagas para estacionamento na área de entorno de edificações pertencentes à Câmara dos Deputados. Foi motivado pelas constantes reclamações em razão da dificuldade em estacionar nas proximidades da Casa, o que vem sendo agravado devido: (a) ao crescimento no número de veículos particulares nas imediações da Câmara e (b) às perspectivas de ampliação do complexo Principal e Avançado da Casa, a partir da construção de novos edifícios, o que implica o remanejamento de áreas de estacionamento, uma maior circulação de veículos particulares e a necessidade de readequação da malha viária.

Para a avaliação foram consideradas informações sobre: (1) quantitativos atuais de vagas; (2) áreas disponibilizadas para o fim e (3) cenário futuro de ocupação. Ao final, foram indicadas as recomendações relacionadas ao tema por meio do estabelecimento de diretrizes entendidas como relevantes para a melhoria das condições de acesso viário, estacionamento e de tráfego, racionalizando a circulação e o trajeto de servidores e visitantes que se dirigem à Casa. Dentre as recomendações, algumas de interesse foram: (1) qualquer proposta de ocupação presente ou futura para a área deve considerar o Plano do Setor de Administração Federal Sul SAFS (Figura 5) principalmente no que se refere ao novo traçado viário; (2) não devem ser realizados investimentos e construções (edificações - provisórias ou definitivas e estacionamentos) em áreas que estejam em desacordo com o referido Plano - entenda-se a ocupação de áreas previstas para vias, segundo o plano de circulação futuro previsto para o SAFS; (3) devem se iniciar discussões para uma articulação entre as instituições beneficiárias e afetadas pelo SAFS (TCU, STJ, Câmara, etc.) e o GDF, no sentido de traçar um Plano de Ocupação e estudos de impacto das ocupações futuras, o que resultaria em subsídios projetuais de longo prazo; (4) estudar, por meio da criação de grupos de trabalho, formas de estimular iniciativas sustentáveis de deslocamento e acesso dos servidores à Câmara ${ }^{16}$; e (5) iniciar a ação integrada das instituições que compõem o SAFS e a Esplanada, junto ao GDF, para estudo e a proposição de melhorias pontuais no sistema de transporte coletivo local. Algumas dessas ações podem ser subsidiadas pelas instituições beneficiárias.

\footnotetext{
${ }^{16}$ Nesse sentido, além de observar a viabilidade de ocupação de novas áreas de estacionamentos, devem-se priorizar as iniciativas de uso do transporte coletivo, não apenas através do reforço e ampliação dos sistemas de integração nos estacionamentos avançados (denominados de "Economildo"), mas principalmente reforçando e ampliando a rota do transporte coletivo exclusivo da Câmara (hoje limitado ao trajeto Rodoviária - Câmara - Rodoviária), ponderada a viabilidade em termos de economicidade
} 


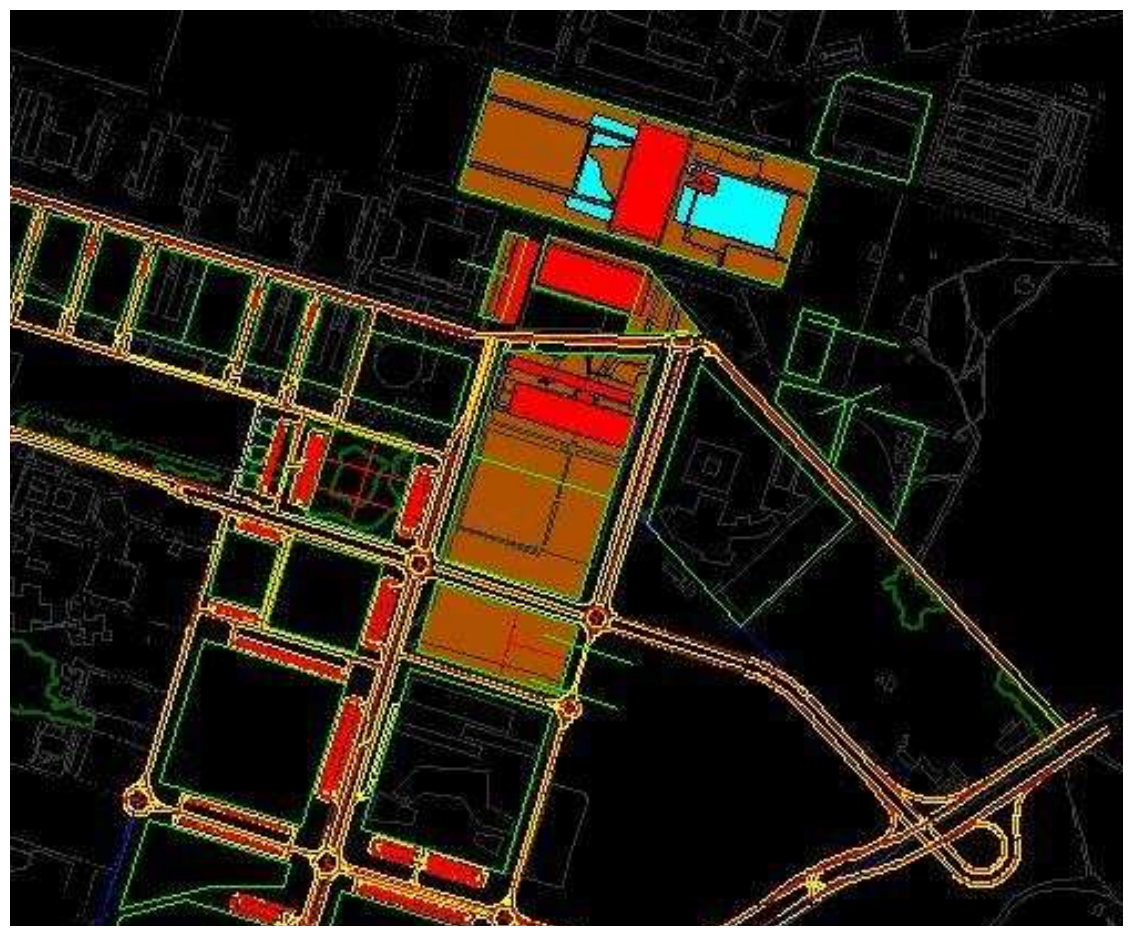

Figura 5 - Sobreposição dos lotes pertencentes ou em processo de doação à Câmara (em marrom) e do novo sistema viário a ser implantado no SAFS (em amarelo e vermelho).

\subsection{Fluxos e movimento}

A análise dos espaços físicos na Câmara dos Deputados exige a consideração de diversos atributos. Um deles corresponde à investigação de fluxos e acessos, fator particularmente importante por se saber que a Casa é composta por diversas edificações e uma das dificuldades recorrentes é a movimentação interna ao longo do Complexo Principal.

Para a análise dos fluxos na Câmara foram utilizados procedimentos de contagem e simulação de movimento em circulações, realizadas por intermédios da sintaxe espacial. A opção baseou-se no fato de que não há dúvidas que certas áreas atraem mais pessoas, enquanto outras menos. Existem fatores "a-espacias" - como localização de lanchonetes, posicionamentos de caixas eletrônicos, costumes e hábitos, tradição, etc. - que promovem ou não a utilização deste ou daquele lugar. Todavia, o que se argumenta aqui é a interferência também de fatores espaciais, como a forma construída e sua maneira de articulação, que são capazes - acredita-se - de condicionar este movimento, conforme reportado por vasta literatura sobre o tema ${ }^{17}$.

Para a análise, considerou-se a elaboração do mapa axial da Câmara, que contemplou as seguintes etapas: (a) sobre uma base do sistema de plantas dos edifícios foram desenhados os eixos que representam os percursos de movimento possíveis (corredores), segundo as barreiras e permeabilidades ao movimento ali existentes; (b) cada linha recebeu automaticamente um

\footnotetext{
${ }^{17}$ Consultar revisão da literatura disponível sobre o tema elaborada por Medeiros (2006).
} 
número de identificação; (c) a malha resultante de eixos, denominada representação linear (Figura 6), foi disposta em um software especialmente desenvolvido para este fim (Depthmap ${ }^{\circledR}$ ), que calculou os valores de conectividade ${ }^{18}$; e (d) na seqüência, produziu os chamados valores de integração.

Estes potenciais numéricos indicam os eixos mais integrados e os mais segregados do sistema a partir da quantificação obtida. Os valores podem ainda ser traduzidos para uma escala cromática, de espessura de linha ou de tons de cinza, o que facilita a leitura imediata e a interpretação dos mapas, apresentando ao observador a variação de potenciais de movimento nos eixos analisados de uma maneira gráfica (Figura 7).

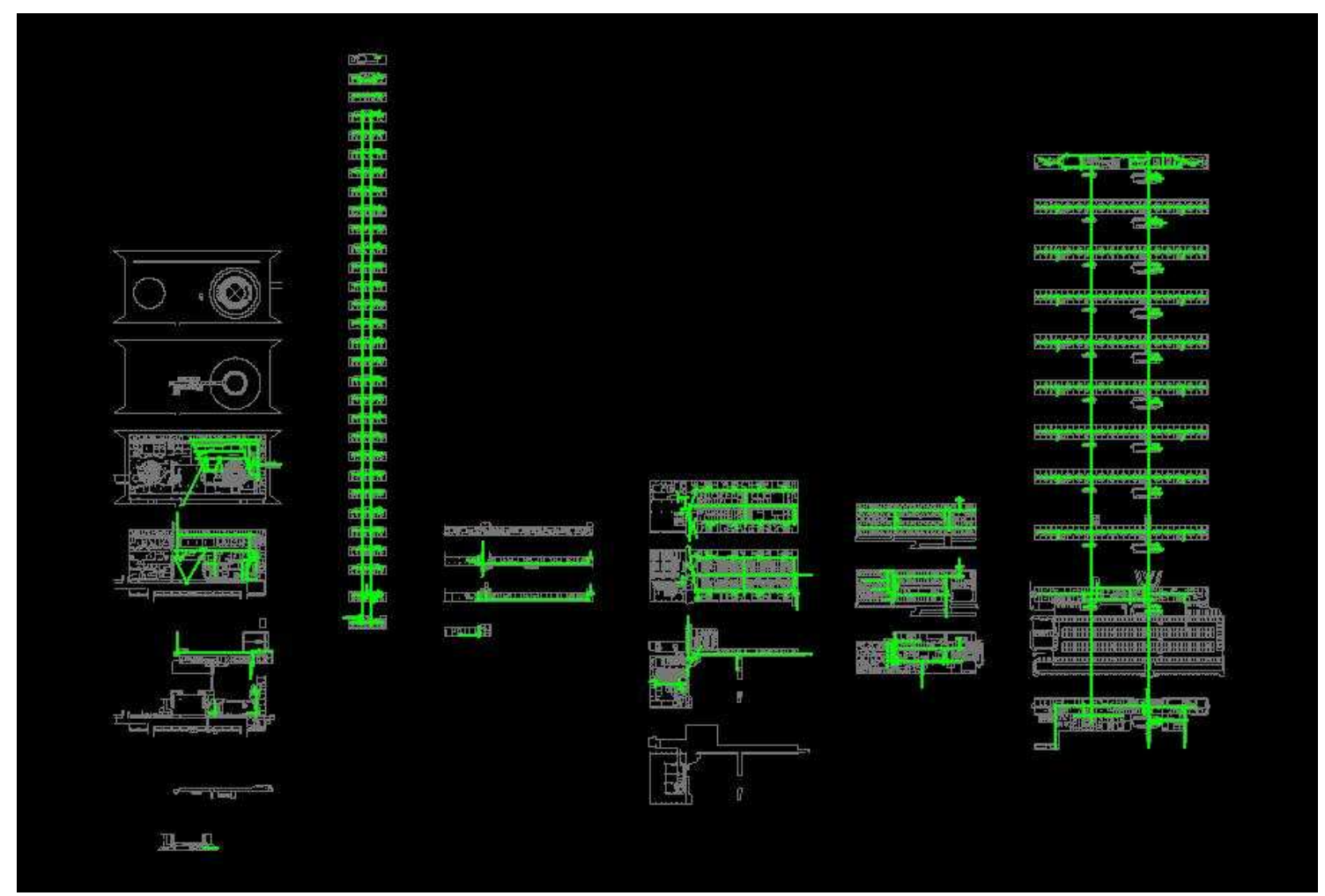

Figura 6 - Representação linear dos eixos de circulação da Câmara dos Deputados.

\footnotetext{
${ }^{18}$ Assume-se que eixos mais conectados são aqueles que apresentam uma maior quantidade de alimentação de portas e outros corredores, e isso já seria um indício para ali haver uma ocorrência de maior quantidade de pessoas. Entretanto, sabe-se que a relação positiva entre conectividade e movimento será dependente do posicionamento de um determinado eixo em um sistema como um todo. Significa que além de uma boa conectividade, é importante que o eixo esteja posicionado centralmente em relação aos demais, sendo que aqui centralidade é uma noção antes topológica do que geométrica e associa-se, diretamente, a uma maior densidade de linhas, independentemente da posição geométrica no espaço. Das conexões entre eixos derivam os chamados valores de integração, que representam o quão acessível (em termos topológicos potenciais, ou seja, desconsiderados fatores outros que não a estrutura espacial) é um determinado eixo em relação a todos os demais em um sistema. Para facilitar a investigação e o tratamento estatísticos dos dados, estes valores de passos médios são normalizados, objetivando também permitir a utilização comparativa dos valores entre diversos mapas, e convertidos para os chamados valores de integração.
} 


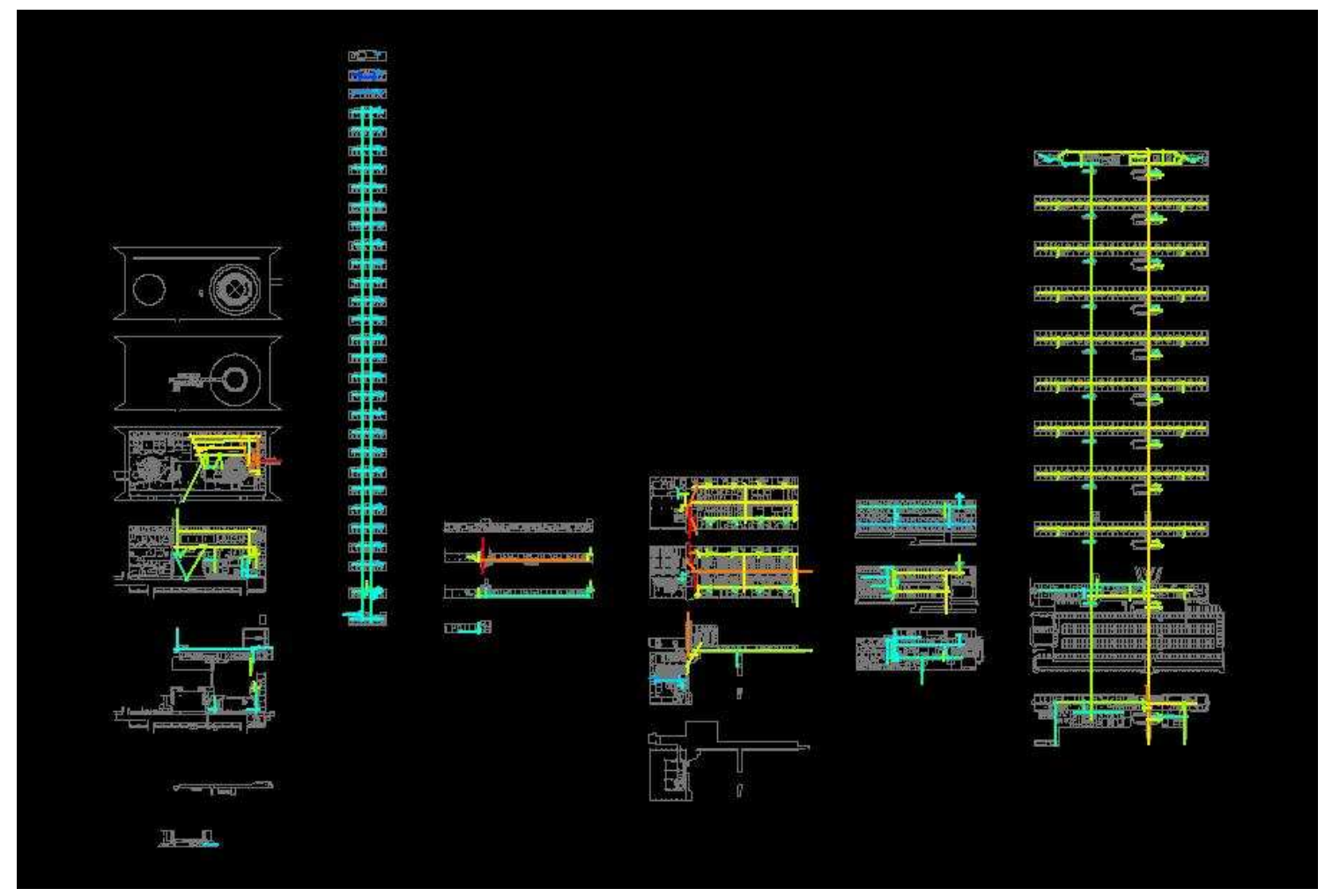

Figura 7 - Mapa axial da Câmara dos Deputados: cores quentes representam eixos potencialmente mais acessíveis, cores frias o contrário.

Para verificar o grau de correlação entre a capacidade de movimento de uma determinada estrutura espacial avaliada por meio do mapa axial e o fluxo real de pessoas, é necessário validar a correspondência. Estudos comprovam que a correlação e a regressão linear entre contagem de pessoas e valores de integração é elevada, entretanto é recomendado confirmar a assertiva para legitimar a aplicação da ferramenta em estudos de planejamento para a Casa.

Para o procedimento de contagem do fluxo real de pessoas circulando ao longo do complexo decidiu-se adotar as gravações do Circuito Fechado de TV da Câmara para 7 câmeras distribuídas no Edifício Principal, Anexo I e corredores entre edificações ${ }^{19}$. Para o alcance dos achados, os valores de integração obtidos por meio do mapa axial foram confrontados com as contagens levantadas para cada ponto de observação das câmeras. Realizados os correspondentes procedimentos estatísticos, encontrou-se $u m \mathrm{R}^{2}$ de $76 \%$ (Figura 8), o que indica uma correlação muito alta, conforme a Escala de Cohen ${ }^{20}$.

\footnotetext{
${ }^{19}$ As gravações são simultâneas e se referem a um mesmo período/dia: 08 de novembro de 2006, quarta-feira, entre as $9 \mathrm{~h}$ e $10 \mathrm{~h}$ da manhã.

${ }^{20}$ Para maiores informações sobre a classificação, ver Jacques (2006).
} 


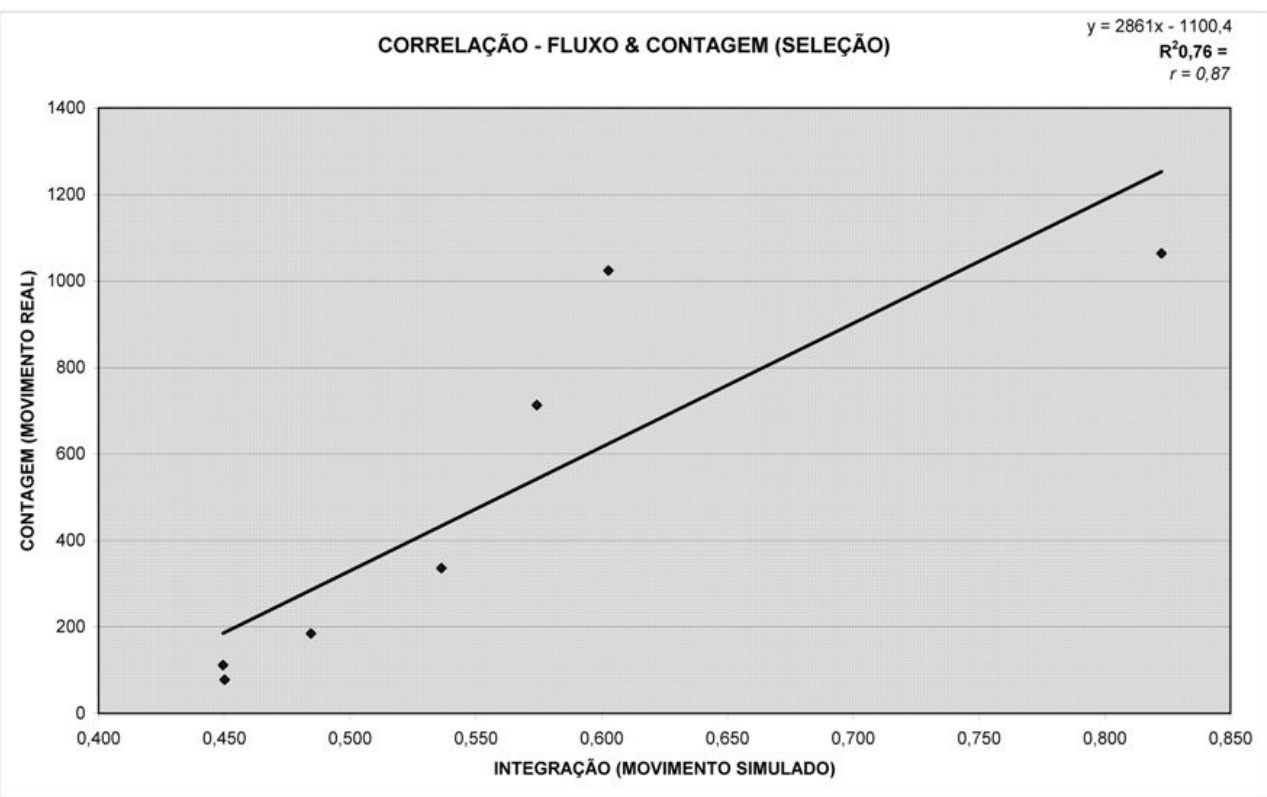

Figura 8 - Correlação entre fluxo simulado por meio do mapa axial e contagem real de indivíduos.

O dado evidencia a aplicabilidade do método para estudos de fluxo, o que possibilitará especialmente a simulação de projetos de intervenção no complexo e suas conseqüências para a circulação entre edifícios - o que é fator crucial para o planejamento do espaço físico na Câmara dos Deputados.

\subsection{O cálculo de densidade}

O estabelecimento de quantidade mínima de metro quadrado por servidor requer a interpretação de um conjunto de condicionantes para a definição de procedimentos que viabilizem o achado de valores de referência que possam ser utilizados como parâmetro de projeto e planejamento do espaço físico. Para a avaliação do caso da Câmara dos Deputados, foram diversos os aspectos ponderados na análise, a saber: (a) inexiste norma ou diretriz oficial que estabeleça o número mínimo de metros quadrados por servidor para um espaço de trabalho, seja de natureza pública ou privada ${ }^{21}$; (b) historicamente os ambientes de trabalho passaram por um progressivo processo de adensamento ${ }^{22}$; (c) a Câmara dos Deputados vem investindo significativamente nos últimos anos na substituição de mesas de madeira por estações de

\footnotetext{
${ }^{21}$ A depender da maneira de organização do mobiliário e do tipo de atividade a ocorrer em um certo ambiente, os valores variam sem que isso signifique, necessariamente, a perda ou o comprometimento da qualidade do espaço construído.

${ }^{22}$ Migrou-se de uma situação baseada em compartimentações intensas, prioritariamente em ambientes de trabalho individuais (até finais do século XIX e início do século XX), para a ideia dos planos livres, conforme enfatizado pelos arquitetos do movimento moderno. A disposição de grandes vãos para espaços de trabalho facilitou a consolidação do padrão das chamadas estações de trabalho que, por seu modo de disposição e arranjo, permitem uma melhor utilização e racionalização da área disponível, maximizando seu uso.
} 
trabalho ${ }^{23}$; e (d) no âmbito do Departamento Técnico, Coordenação de Projeto e Seção de Gerenciamento e Planejamento dos Espaços Físicos da Casa, são constantes as solicitações por áreas oriundas de órgãos internos e externos da $\mathrm{Casa}^{24}$.

Remetendo aos condicionantes apontados previamente, para o cálculo de referência na Câmara dos Deputados foram considerados como amostragem o cálculo da metragem quadrada dos ambientes em relação ao número de postos de trabalho nele localizados, segundo levantamentos in loco para 3 situações específicas: (a) Situação 1 - Edifício Anexo II - Todos os ambientes de trabalho do edifício Anexo II, distribuídos em seus 4 níveis de pavimentos (Subsolo 2, Subsolo 1, Térreo e Superior), foram computados; (b) Situação 2 - Pregão 51 Para o cálculo foram verificados todos os projetos de instalação de novo mobiliário (estações de trabalho) associados ao Pregão 51; e (c) Situação 3 - Amostra para o Edifício Anexo IV - Aqui foram avaliados os graus de saturação e densidade dos gabinetes parlamentares situados em 3 pavimentos do Edifício Anexo IV $\left(2^{\circ}, 3^{\circ}\right.$ e $4^{\circ}$ Pavimentos). A escolha considerou esta edificação por ser o mais emblemático ambiente de trabalho legislativo na Câmara dos Deputados, a ponderar a existência de 513 gabinetes para os Deputados no Complexo Arquitetônico Principal da Casa.

Sobre o procedimento, importa esclarecer que: (a) para o cálculo da metragem quadrada por servidor, adotou-se a referência da razão entre a área do ambiente e o número de postos de trabalho ali localizados; (b) foram considerados apenas ambientes efetivamente de trabalho; (c) as salas exclusivas/restritas, incluindo ambientes de reprografia, arquivo, almoxarifado, foram desconsideradas em razão de sua peculiaridade ${ }^{25}$; (d) preferiu-se a indicação de postos de trabalho por ambiente e não de número de funcionários por ambiente, tendo em vista que o primeiro valor representa o número efetivo de servidores trabalhando simultaneamente em um certo local; e (e) a categoria posto de trabalho corresponde a uma superfície de trabalho (mesa, bancada ou estação de trabalho) que abriga um servidor desempenhando suas atividades ${ }^{26}$.

A síntese dos cálculos está apresentada na Tabela 1, computada segundo as categorias amostrais para variados ambientes da Câmara dos Deputados, a partir dos procedimentos

\footnotetext{
${ }^{23}$ De fato há o caráter de contemporaneidade e de visão empresarial/corporativa associada simbolicamente ao novo mobiliário e, além disso, a estratégia tem permitido o adensamento dos ambientes de trabalho e a ocupação máxima dos espaços. Sabe-se, entretanto, que a ação requer estudos mais aprofundados de modo a relacionar, ao tema, discussões sobre densidade e segurança.

${ }^{24}$ É sabido o estado de saturação dos espaços na Câmara, conforme demonstrado pelo Caderno Técnico 01 - Espaços Físicos. No documento foi apontado que, para uma melhoria na qualidade do ambiente de trabalho na Casa, seria necessário não somente efetivar o discurso de ampliação dos complexos arquitetônicos pertencentes ao órgão, como também estabelecer o remanejamento e o reordenamento de órgãos, o que significaria a aplicação de procedimentos de compensação de área e a utilização de estratégias de substituição de mobiliário, como aquela associada às estações de trabalho.

${ }^{25}$ Igualmente nesta categoria, e para não mascarar os dados, ambientes de chefes foram descartados por apresentarem uma metragem que usualmente não corresponde à situação efetiva naquele órgão.

${ }^{26}$ Para ser considerado posto de trabalho, não é necessário haver computador na superfície: a característica é dependente da natureza da atividade em curso.
} 
apontados no tópico anterior. O valor final obtido $\left(5,11 \mathrm{~m}^{2} /\right.$ posto) tem sido utilizado para as recomendações projetuais, bem como indicador vinculado ao planejamento estratégico da Casa.

Tabela 1 - Quadro comparativo da média m2/posto de trabalho na Câmara dos Deputados, segundo a amostra.

\begin{tabular}{l|c|c|c|c}
\hline EDIFÍCIO & PAVIMENTO & ÁREA TOTAL & NÚMERO DE PT & MÉDIA M'/PT \\
\hline SITUAÇÃO I & $7.124,09$ & 1243 & 5,73 \\
\hline SITUAÇ̃̃O II & $2.705,65$ & 533 & 5,08 \\
\hline SITUAÇÃ̃ III & $3.284,49$ & 792 & 4,15 \\
\hline Média Global & $\mathbf{1 3 . 1 1 4 , 2 3}$ & $\mathbf{2 5 6 8}$ & $\mathbf{5 , 1 1}$ \\
\hline
\end{tabular}

\section{Algumas Recomendações}

A problemática de ocupação dos espaços físicos e qualidade nos ambientes de trabalho na Câmara dos Deputados parece resultar de uma combinação de fatores, dentre os quais predomina o desequilíbrio quanto à distribuição de áreas, fonte potencial de conflitos em um quadro fortemente marcado por determinações de ordem política, dada a natureza da instituição.

Estudos elaborados pelo Núcleo de Arquitetura da Coordenação de Projetos do Detec (CT01, 2007 a CT05, 2007), a partir de uma série de desconfortos, inadequações e perdas na realização das atividades fim e meio da Casa, apontou que iniciativas de planejamento espacial na Câmara dos Deputados devem considerar simultaneamente duas estratégias de intervenção física: (1) tamanho, correspondente à ampliação da área espacial da Casa, especialmente em relação ao entorno do Complexo Principal, por meio do aproveitamento de potenciais construtivos de lotes pertencentes à Casa; e (2) arranjo, desenvolvido segundo uma proposta de reordenamento espacial dos usos e atividades dispostas nos edifícios da Câmara, segundo avaliações de densidade versus segurança, população e compatibilidade de áreas, etc.

Os dois focos devem ser balizados de acordo com a legislação vigente (urbanística, patrimonial, trabalhista, etc.), conformados a partir de aspectos científicos, metodológicos e técnicos que priorizem o alcance de um status adequado de qualidade espacial dos ambientes de trabalho na Casa com vistas à boa organização e funcionamento do parlamento.

Esta pesquisa, portanto, dialogou com tais achados preliminares, colaborando para a ênfase na necessidade de um estudo minucioso, e continuado, sobre a distribuição e qualidade espacial dos ambientes e órgãos pertencentes ao organograma da Câmara dos Deputados, confrontados com as correspondentes implicações para a realização das atividades legislativas.

Consideramos ser fundamental para o entendimento da temática a investigação e discussão do espaço físico e das atividades relativas à elaboração de leis, com base no princípio de forma-espaço, e mais específicamente, como sua leitura no complexo arquitetônico da instituição pode auxiliar em ações reflexivas sobre a configuração espacial do lugar. Por ação reflexiva entende-se o conjunto de estratégias para avaliar o espaço construído, desde sua construção temporal à exploração de cenários futuros, conforme desígnios de ordem funcional e, 
por vezes simbólica, em perspectivas temporais distintas. Inclui, também, o confronto entre exemplares, validando achados e construindo identidades/distinções a partir de amostras.

Significa que todos os focos contemplados no planejamento aqui arrolados e discutidos têm por fim as implicações na forma-espaço e no entendimento de como certos atributos interferirão no elemento construído e na realização/desenvolvimento das atividades. Os atributos seriam aqueles incidentes na qualidade do espaço, a incluir aspectos como: (1) Configuração Espacial e ocupação atual - os arranjos, a articulação e o relacionamento entre espaços correntemente utilizados; (b) População Existente - perfil e quantidade de indivíduos que utilizam os espaços, suas demandas, carências, saturações, incômodos, etc.; (c) Carências e Desígnios identificados mediante observação e consulta aos usuários conforme suas correspondentes rotinas de trabalho; (d) Potenciais Construtivos e Adequabilidades identificação de novos espaços disponíveis, ou melhor adequação desses espaços para certos usos; e (e) Legislação - aspectos legais que condicionam a apropriação e utilização dos espaços (municipais, distritais, estaduais, federais, ABNT, etc.).

Avalia-se que o artigo, que compreende ações do Grupo de Pesquisa e Extensão "A investigação da forma-espaço em edifícios complexos: estratégias para gerenciamento e planejamento de espaço físico na Câmara dos Deputados", esclarece aspectos relativos à associação entre forma-espaço e desempenho de atividades profissionais, contribuindo para fundamentar cientificamente a tomada de decisões projetuais e administrativas.

O produto da continuidade do trabalho, a contribuir para a elaboração de um plano diretor de usos dos espaços e construído segundo procedimentos teóricos, metodológicos e ferramentais precisos, compreenderá um conjunto de recomendações e princípios delineadores para uma melhor distribuição espacial no órgão. Acredita-se que as etapas futuras precisam contemplar a consolidação da base de dados espacial que, segundo (a) utilização adequada, (b) atualização dinâmica e (c) consulta democrática a partir de níveis de acesso, poderá se tornar uma robusta ferramenta de auxílio para a concepção espacial na Câmara. Espera-se, deste modo, que os achados associados à efetivação de tais ações de planejamento de edificação complexa possam subsidiar decisões tecnicamente fundamentadas, construindo uma rotina que pondere o planejamento global e o entendimento que alterações localizadas têm, em graus variados, implicações para o complexo por inteiro.

Os achados e processos resultantes da pesquisa, e das iniciativas afins que já vem sendo tomadas pela Coordenação de Projetos desde novembro de 2006, esclarecem a necessidade de se construir um sistema de informações para gerenciamento e planejamento dos espaços físicos na Câmara dos Deputados. Para planejar um espaço - qualquer que seja a escala, principalmente em edificações complexas já em uso, é relevante conhecer, com grau de confiança e precisão, qual o quadro atual e passado daquele local para, a partir daí, estimar as demandas futuras. 
Acreditamos que um nível satisfatório de confiabilidade dos dados poderá ser atingido por meio de estratégias de organização, controle, análise e atualização de informações, ancoradas em procedimentos conceituais claramente definidos, atitude particularmente relevante em uma instituição onde a variável legislativa/política impõe condicionantes para além da alçada técnica.

Ademais, ao serem inseridas rotinas de simulações futuras, como ocorre no caso dos parâmetros de circulação, será possível estabelecer cenários com antecedência, melhor delineando iniciativas gerenciais. E não apenas: produtos como o que se apresenta poderão fornecer parâmetros para legislações associadas, planos diretores, planos de manejo, minutas de planejamento, intenções projetuais e mesmo decisões localizadas, o que cristalizará sua utilidade para as ações sobre os espaços físicos na Câmara dos Deputados.

O fato é particularmente útil num momento em que a administração da Casa, por meio do patrocínio de ações de planejamento e gestão estratégica, inicia programas e projetos corporativos estruturantes. Em abril de 2009, foram lançados 11 projetos e programas “considerados estruturantes para o salto qualitativo da gestão estratégica da Câmara dos Deputados para os próximos anos", por serem aqueles que causarão maiores impactos nos objetivos do mapa corporativo (Plano, 2009). Um deles é o "Plano Diretor de Uso dos Espaços”, que compreende a definição de política para o reordenamento e racionalização dos espaços construídas da Casa, com a incorporação de conceitos de acessibilidade e sustentabilidade (em seus correspondentes âmbitos ampliados), tendo em vista o propósito de assegurar condições adequadas de trabalho no órgão.

\section{Referências}

APPEL-MEULENBROEK, Rianne. Knowledge sharing in research buildings and about their design. In: $7^{\text {th }}$ SSS, 2009, Estocolmo - Suécia. Proceedings... Estocolmo: KTH, 2009.

CAPRA, Fritjof. A teia da vida: uma nova compreensão científica dos sistemas vivos. 8 ed. São Paulo: Pensamento-Cultrix, 2003.

COUTINHO, Evaldo. O espaço da arquitetura. 2. ed. São Paulo: Perspectiva, 1998.

CT01 (Planejamento dos espaços físicos). Brasília: SEGEP/NUAR/CPROJ/DETEC/ Câmara dos Deputados, 2007 (mimeo).

CT02 (CEFOR: avaliação dos espaços físicos). Brasília: SEGEP/NUAR/CPROJ/ DETEC/Câmara dos Deputados, 2007 (mimeo).

CT03 (CENIN: avaliação dos espaços físicos). Brasília: SEGEP/NUAR/CPROJ/ DETEC/Câmara dos Deputados, 2007 (mimeo).

CT04 (Acessibilidade viária e estacionamentos). Brasília: SEGEP/NUAR/CPROJ/ DETEC/Câmara dos Deputados, 2007 (mimeo).

CT05 (Densidade e grau de saturação espacial). Brasília: SEGEP/NUAR/CPROJ/DETEC/ Câmara dos Deputados, 2007 (mimeo).

FORESTI, Celina; HAMBURGER, Diana Sarita. Sensoriamento remoto aplicado ao estudo do uso do solo urbano. In: TAUK, Sâmia Maria. Análise Ambiental: uma visão multidisciplinar, 2. ed. São Paulo: Editora UNESP, 1995. 
HILLIER, Bill. A theory of the city as object,. In: $3^{\text {rd }}$ SSS, 2001, Atlanta - EUA. Proceedings... GeorgiaTech/University of Michigan, 2001, p. 02.1-02.28.

HILLIER, Bill. Space is the machine. Londres: Cambridge University Press, 1996.

HILLIER, Bill; HANSON, Julienne. The social logic of space. Cambridge: CPU, 1984.

HOLANDA, Frederico. Arquitetura sociológica. In: Revista Brasileira de Estudos Urbanos e Regionais. São Paulo, 2007, v. 9, n. 1, p. 115-129.

JACQUES, Maria Alice Prudêncio. Comunicação Particular. Brasília, 2006.

MEDEIROS, Valério A. S. de. Urbis Brasiliae ou sobre cidades do Brasil. Brasília, 2006. Tese - PPG-FAU/UnB.

PLANO - PLANO ESTRATÉGICO CORPORATIVO: Câmara dos Deputados. Disponível em $<$ http://www2.camara.gov.br/conheca/gestaoestrategica/plano-estrategicocorporativo/?searchterm=Planejamento\%20Estratégico $>$. Acesso em: 20 jun. 2009.

SAILER, Kerstin, PENN, Alan. Spatiality and transpatiality in workplace environments. In: $7^{\text {th }}$ SSS, 2009, Estocolmo - Suécia. Proceedings... Estocolmo: KTH, 2009.

STEEN, Jesper. Spatial and social configurations in offices. In: $7^{\text {th }}$ SSS, 2009, Estocolmo Suécia. Proceedings... Estocolmo: KTH, 2009.

Artigo recebido em: 17/02/2010

Artigo aceito para publicação em: 28/04/2010 